\title{
NEW WATER MITE SPECIES OF THE GENUS KONGSBERGIA (ACARI, HYDRACHNIDIA, ATURIDAE) FROM TURKEY
}

\author{
PinAR Gülle ${ }^{1}$ and Yunus ÖMer BoyaCI ${ }^{2}$ \\ ${ }^{1}$ Mehmet Akif Ersoy University, Faculty of Science and Arts, Burdur, Turkey \\ E-mail: pnarozsimsek@gmail.com, https://orcid.org/0000-0003-1347-4283 \\ ${ }^{2}$ Isparta University of Applied Sciences. Ë̆irdir Fisheries Faculty, Isparta, Turkey \\ E-mail: yboyaci@gmail.com, https://orcid.org/0000-0002-4027-4482
}

In this study, there is a description of a new species, Kongsbergia ermani sp. n. and Kongsbergia largaiollii (Maglio, 1909) representing a new Kongsbergia record for the fauna of Turkey.

Keywords: Acari, new water mite species, Kongsbergia, fauna, Turkey, taxonomy.

\section{INTRODUCTION}

Water mites of the genus Kongsbergia Thor, 1899 are widely distributed in all biogeographical realms, except for Australia and Antarctica. The highest number of species have been reported from the Holarctic region (PEšıć et al. 2020). All known species were found exclusively in surface interstitial habitats of streams. The characteristic sexual dimorphism in Kongsbergia involves mostly IV-L-4-6 (GERECKe et al. 2016). Species diagnoses are usually based on males.

Kongsbergia ermani sp. n. collected from Köprüçay river was described in this study. Besides, Kongsbergia largaiollii (Maglio, 1909) collected from a small creek that feeds the same river has been newly recorded for the Turkish water mite fauna.

\section{MATERIAL AND METHODS}

Water mites were collected using hand netting and sorted on the spot from other living material. They were then preserved in Koenike's fluid (50\% glycerin, $20 \%$ acetic acid, 30\% distilled water). The specimens were dissected and slide-mounted in Hoyer's medium, then deposited in the Faculty of Fisheries, Süleyman Demirel University (SDU), Isparta, Turkey. The composition of the material is given as males/females. All measurements are given in micrometres $(\mu \mathrm{m})$. The following abbreviations are used:, $\mathrm{Cx}-\mathrm{I}=$ first coxae; Dgl = dorsoglandularia, $\mathrm{H}$ = height; I-L-4-6 = fourth-sixth segments of first leg; $\mathrm{L}=$ length; $\mathrm{n}=$ number of specimens examined, $\mathrm{P}-1-5=$ palp segment $1-5 ; \mathrm{W}=$ width .

\section{RESULTS}

Family Aturidae Thor, 1900

Genus Kongsbergia Thor, 1899 


\section{Kongsbergia ermani sp. $n$.}

Type material. Holotype male, a fast-flowing stream with sand and gravel bottom, 22.06.2008, $37^{\circ} 44^{\prime} 44^{\prime \prime} \mathrm{N}, 31^{\circ} 01^{\prime} 38^{\prime \prime} \mathrm{E}, 1188 \mathrm{~m}$ a.s.l., Köprüçay River, Isparta, Turkey (Fig. 1). Paratypes: 3/0 same data as holotype, leg. Y. Ö. Boyac1.

Diagnosis. P-2 very enlarged, a large thin long projection in the ventral and a small projection in the distoventral. IV-L-5 shortened, ventral margin with one projection, proximal seta away from segment base and proximal seta bent forward and thinner than the central seta on the projection. The distoventral seta, which is located between the central seta and the tip of the segment, is thick and small. There is a long and thin seta above the distoventral seta and a small, thick and curved seta next to the long seta. IV-L-6 extremely enlarged and strong claws.

Male. Holotype, in parentheses variability of the paratypes given as mean $(n=3)$. Idiosoma enlarged anteriorly, narrowed posteriorly, L/W 370 (375) / 250 (253) (Fig. 3b), lenses with three-pieces, preantenniform setae distance L 35 (36), mouth opening L/W 110 (112) / 75 (76) (Fig. 3a), capitulum L 145 (147) (Fig. 4a).

Commissure except for Cx-1 and 2 completely missing, with only vague scars (Fig. 3a).

$\mathrm{P}-2$ very enlarged, a large thin long projection in the anteroventral and a small projection in the distoventral P-1-5 L: 22(23)-108(110)-47(48)-104(106)-40(40) = 321, H: 29(29)97(98)-60(59)-30(30)-17(17) (Fig. 4a).

IV-L-5 shortened, ventral margin with one projection, proximal seta away from segment base and proximal seta bent forward and thinner than the central seta on the projection (not pectinate). The distoventral seta, which is located between the central seta and the tip of the segment, is thick and small. There is a long and thin seta above the distoventral seta and a small, thick and curved seta next to the long seta. IV-L-6 extremely enlarged and strong claws. (Figs $4 b, c)$.

I-L 48(48)-64(64)-53(54)-58(59)-76(76)-93(93) = 392(394), II-L 48(49)-66(67)-55(55)59(60)-68(68)-98(98) = 394(397), III-L 50 (51)-60(60)-54(55)-65(66)-88(89)-107(107) = 424 (427), IV-L 85(85)-58(59)-73(73)-78(79)-82(82)-84(85) = 460(463).

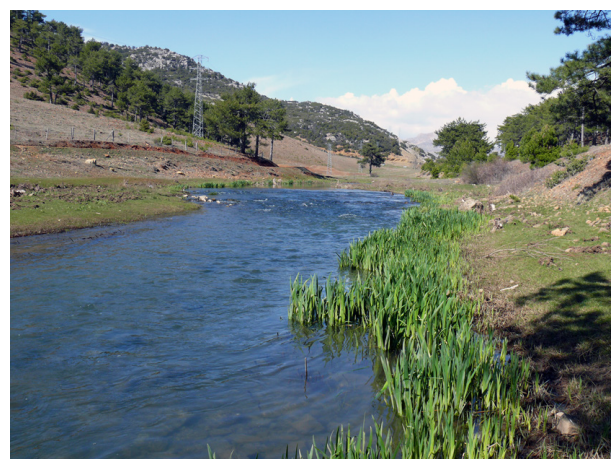

Fig. 1. Habitat of Kongsbergia ermani sp. n.

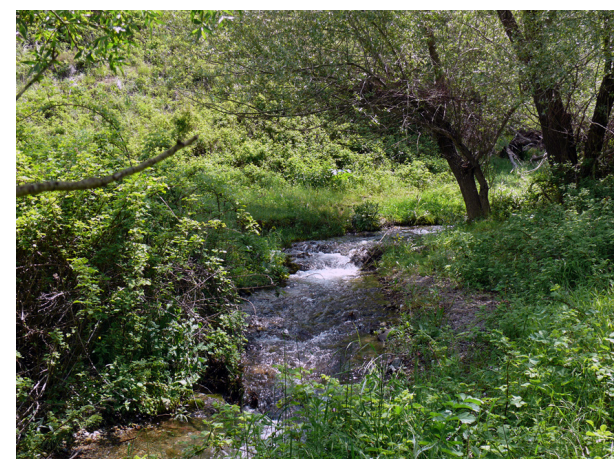

Fig. 2. Habitat of Kongsbergia largaiollii 
The gonopore located in the posterior part of the abdominal plate and surrounded by a round chitin ring (Fig. 3a).

Etymology. The species name is given in honour of the water mite specialist Prof. Dr. Orhan Erman.

Remarks. The closest species to Kongsbergia ermani is Kongsbergia simillima K. Viets, 1949. The features that distinguish it from this species are as follows: (1) P-2 basal half of ventral margin has 2 projections (K. simillima has 3 projections), P-4 near ventral setae insertion forming an obtuse angle, from here to tip concave in K. simillima (2) The proximal seta in K. ermani is longer and not pectinate (ventrally pectinate in K. simillima) on IV-L-5 (3) distoventral seta K. simillima is also very small curved and at the end of the segment. The distoventral seta in K. ermani, which is located between the central seta and the tip of the segment, is thicker and bigger (4). IV-L-6 is wider and shorter than K. simillima ( $\mathrm{L} / \mathrm{H}$ ratio 3.4), and its $\mathrm{L} / \mathrm{H}$ ratio is 1.63 (5) forward elongated idiosoma, wide mouth opening, gonopore with round chitin ring in K. ermani.

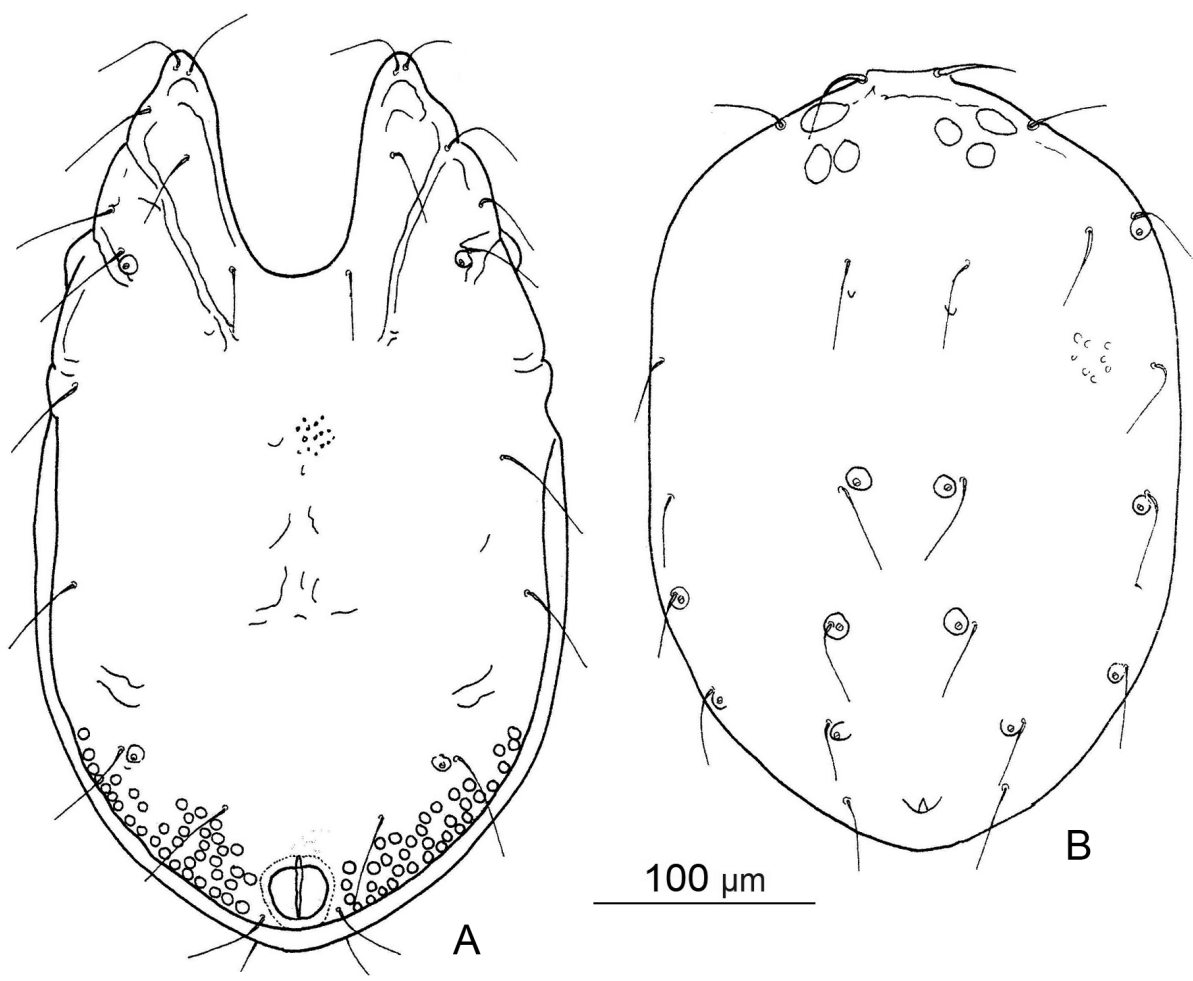

Fig. 3. Kongsbergia ermani sp. n., male a) idiosoma, ventral view b) idiosoma, dorsal view 
Kongsbergia largaiollii (Maglio, 1909)

Studied samples and living areas. Hisarard 1 spring water, 3/0, 20.07.2008, 38 $19^{\prime} 37^{\prime \prime} \mathrm{N}$, $31^{\circ} 15^{\prime} 45^{\prime \prime} \mathrm{E}, 1351 \mathrm{~m}$ a.s.l., Yalvaç, Isparta, Turkey (Fig. 2). A small stream with slowly flowing, sandy bottom that flows into the Köprüçay River, 18.06. 2008, 1/0, Eğirdir, Isparta, Turkey.

Description. As given in Gerecke et al. (2016).

Measurements. Male. L/W 323/228, mouth opening L/W 103/55, capitulum L/H 105 / 84. P-1-5 L 32-86-34-93-40 = 285, H 27-80-50-32-15. I-L 40-60-51-54-72-90 = 377, II-L 40-63$52-55-66-96=372$, III-L 50-57-50-60-84-100 = 401, IV-L 55-90-66-78-78-93 = 449 .

Distribution. Southern and central Europe, British Isles (GEREcKe et al. 2016). New record for Turkey.

Remarks. It is distinguished from related species by an anterior wide and posterior-narrow idiosoma structure, $\mathrm{Cx}-4$ protrusion on the sides, sexual aperture appendage longer than idiosoma length, relatively chunky IV-L and short IV-L-5, very small and thin proximal seta, thick, long, bent forward central seta (GERECKE et al. 2016).

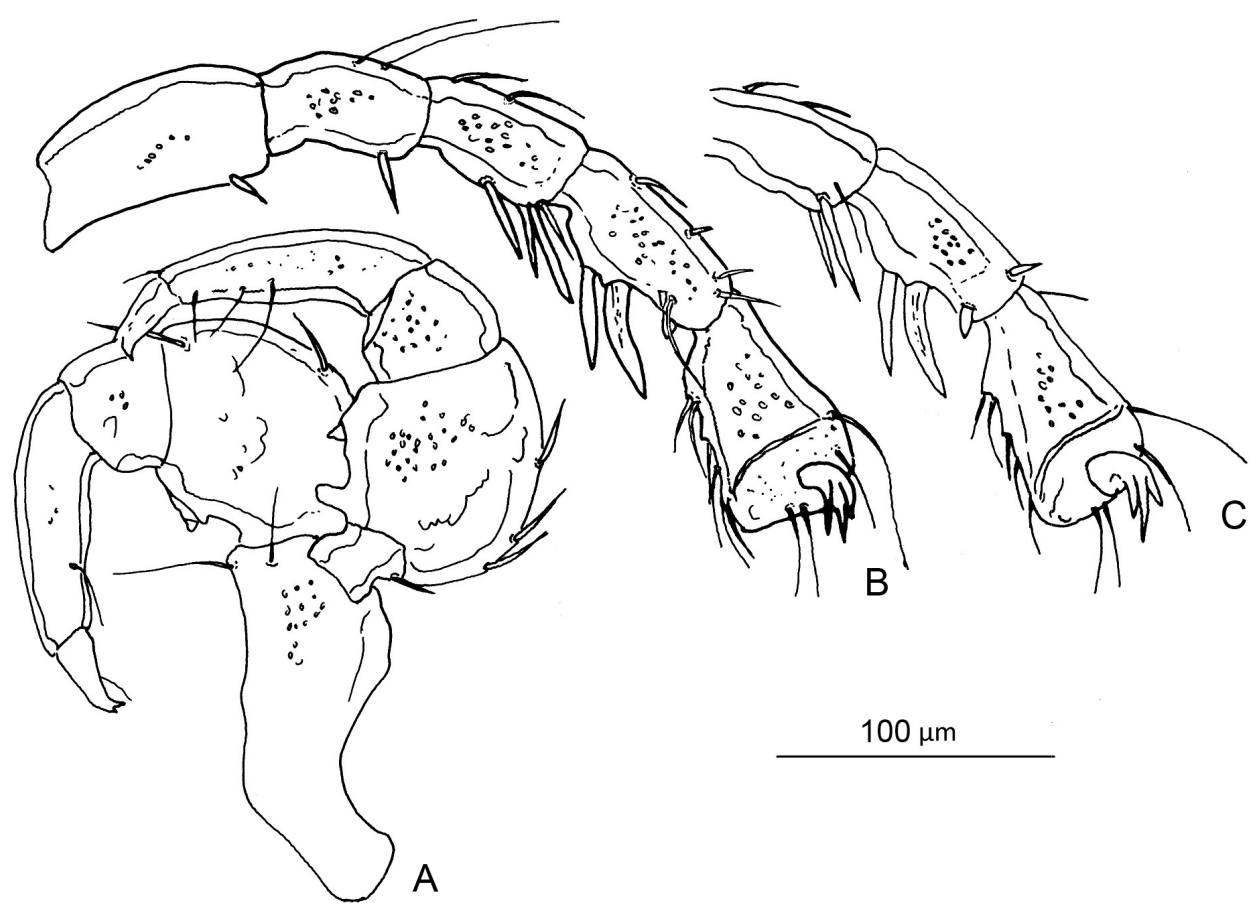

Fig. 4. Kongsbergia ermani sp. n., male a) gnathosoma b) IV-L outside view c) IV-L inside view 


\section{DISCUSSION}

Before this study, there were known two species of this genus in Turkey (ERman et al. 2010, Erman et al. 2019). With these new records, the number of Kongsbergia species is increased to four. Kongsbergia species identification keys of Turkey was prepared according to the shape and setation of IV-L-5-6 segments of male individuals, which are of great importance in determining the species of this genus (EsEn et al. 2011, GERECKE et al. 2016).

\section{Key to species of the genus Kongsbergia from Turkey}

IV-L-5 shortened, ventral margin with one projection, proximal seta away from segment base and proximal seta bent forward and thinner than the central seta on the projection. The distoventral seta, which is located between the central seta and the tip of the segment, is thick and small K. ermani sp. n.

IV-L-5 proximoventral seta short and slender, located proximally to a triangularventral projection in segmentcentre which bears the strong, long, curved medioventral seta; anterior to the projection ventral margin concave, distoventral seta slender and short, 2 pectinate setae at distal margin

K. largaiollii

IV-L-5 ventral margin with basal kink, convexly protruding in the centre, and here abruptly narrowed forming a pointed tip that separates the short weakly curved proximoventral seta from the very strong, slightly undulating and apically truncates medioventral seta; distoventral seta hookshaped

K. materna

Thickened, wavy-shaped proximal seta originating on a ventroproximal projection of IV-L-5, the distal sword-shaped seta exceeding distal margin of IV-L-5 and the ventral side of I-L-5 bearing one seta

K. persica

Acknowledgements - We are very thankful to Reinhard Gerecke (Tübingen, Germany) for valuable suggestions. This study was supported by the Scientific and Technical Research Council of Turkey (Project no:107 T 321 TBAG). We thank two anonymous reviewers for improving the manuscript. 


\section{REFERENCES}

Erman, O., Pešić, V., Esen, Y. \& Özkan, M. (2010): A checklist of the water mites of Turkey (Acari: Hydrachnidia) with description of two new species. - Zootaxa 2624: 1-48. https://doi.org/10.11646/zootaxa.2624.1.1

Erman, O., Gülle, P., Özkan, M., CandoĞan, H. \& Boyaci, Y. Ö. (2019): Checklist of the water mites (Acari: Hydrachnidia) of Turkey: First supplement. - Zootaxa 4686(3): 376-396. https://doi.org/10.11646/zootaxa.4686.3.4

Esen, Y., Pešić, V. \& Erman, O. (2011): Water mites of the family Aturidae Thor, 1900 from Turkey (Acari: Hydrachnidia), with description of two new species. - Zootaxa 2746: 25-42. https://doi.org/10.11646/zootaxa.2746.1.3

Gerecke, R., Gledhill, T., Pešić, V. \& Smit, H. (2016): Chelicerata: Acari III. In: Gerecke, R. (ed.): Süßwasserfauna von Mitteleuropa 7. 2 (3). - Springer, Heidelberg, 429 pp. https:// doi.org/10.1007/978-3-8274-2689-5

Pešić, V., Smit, H. \& Bahuguna, P. (2020): A new species of Kongsbergia from the Western Himalaya with a key to the species of the genus of India (Acari: Hydrachnidia). - Ecologica Montenegrina 27: 35-38. https://doi.org/10.37828/em.2020.27.4

Received October 14, 2020, accepted November 13, 2020, published February 22, 2021 